\title{
Gastric tumor development in Smad3-deficient mice initiates from forestomach/glandular transition zone along the lesser curvature
}

\author{
Ki Taek Nam ${ }^{1,2,3}$, Ryan O'Neal ${ }^{2,3}$, Yeo Song Lee ${ }^{4}$, Yong Chan Lee ${ }^{4}$, Robert J Coffey ${ }^{1,3,5,6}$ and \\ James R Goldenring ${ }^{1,2,3,6}$
}

SMAD proteins are downstream effectors of the TGF- $\beta$ signaling pathway. Smad3-null mice develop colorectal cancer by 6 months of age. In this study, we have examined whether the loss of Smad3 promotes gastric neoplasia in mice. The stomachs of $\mathrm{Smad}^{-1-}$ mice were compared with age-matched Smad3 heterozygous and wild-type mice. E-cadherin, Ki-67, phosphoSTAT3, and TFF2/SP expression was analyzed by immunohistochemisty. The short hairpin RNA (ShRNA)mediated knockdown of Smad3 in AGS and MKN28 cells was also performed. In addition, we examined alterations in DCLK1-expressing cells. Smad3 ${ }^{-1-}$ mouse stomachs at 6 months of age revealed the presence of exophytic growths along the lesser curvature in the proximal fundus. Six-month-old Smad3 ${ }^{-1-}$ mouse stomachs showed metaplastic columnar glands initiating from the transition zone junction between the forestomach and the glandular epithelium along the lesser curvature. Ten-month-old Smad ${ }^{-/-}$mice all exhibited invasive gastric neoplastic changes with increased Ki-67, phosphoSTAT3 expression, and aberrant cytosolic E-cadherin staining in papillary glands within the invading submucosal gland. The shRNA-mediated knockdown of Smad3 in AGS and MKN28 cells promoted the expression of phosphoSTAT3. DCLK1-expressing cells, which also stained for the tuft cell marker acetylated- $\alpha$-tubulin, were observed in 10-month-old Smad3 ${ }^{-1-}$ mice within tumors and in fundic invasive lesions. In conclusion, Smad3-null mice develop gastric tumors in the fundus, which arise from the junction between the forestomach and the glandular epithelium and progress to prominent invasive tumors over time. Smad3-null mice represent a novel model of fundic gastric tumor initiated from forestomach/glandular transition zone along the lesser curvature.

Laboratory Investigation (2012) 92, 883-895; doi:10.1038/labinvest.2012.47; published online 12 March 2012

KEYWORDS: animal model; DCLK1; forestomach; gastric tumor development; Smad3; SPEM; tuft cell

Gastric cancer remains the fourth most commonly diagnosed cancer globally and the second most common cause of cancer mortality, worldwide. ${ }^{1}$ The most common types of gastric cancer are adenocarcinomas. Gastric adenocarcinomas develop throughout the stomach and are often defined by regional location as proximal, fundic, incisural or distal (antral). Over the past 30 years, in western countries, there has been a shift towards an increase in the frequency of gastric cancers arising in the proximal stomach compared with the antrum. ${ }^{2}$ Functionally, the human gastric mucosa is divided into the oxyntic gland area and the pyloric gland area. The proximal $80 \%$ of the stomach, including the mucosa of the body and fundus, is occupied with the oxyntic area, which secretes acid and pepsinogen. Gastric adenocarcinomas of the intestinal type are believed to develop through a process of multiple stages that include chronic gastritis, oxyntic atrophy, foveolar hyperplasia and metaplasia. $^{3}$

Smads are recognized as downstream intracellular proteins in the signaling of transforming growth factor $\beta$ (TGF- $\beta$ ), which is mediated through a heteromeric complex of two types of transmembrane receptors: TGF- $\beta$ recepter type

\footnotetext{
${ }^{1}$ Nashville Department of Veterans Affairs Medical Center, Vanderbilt University School of Medicine, Nashville, TN, USA; ${ }^{2}$ Department of Surgery, Vanderbilt University School of Medicine, Nashville, TN, USA; ${ }^{3}$ Epithelial Biology Center, Vanderbilt University School of Medicine, Nashville, TN, USA; ${ }^{4}$ Brain Korea 21 Project for Medical Science and Department of Internal Medicine, Yonsei University College of Medicine, Seoul, Korea; ${ }^{5}$ Department of Medicine, Vanderbilt University School of Medicine, Nashville, TN, USA and ${ }^{6}$ Department of Cell and Developmental Biology, Vanderbilt University School of Medicine, Nashville, TN, USA

Correspondence: Dr KT Nam, DVM, PhD, Epithelial Biology Center, Vanderbilt University School of Medicine, MRB IV, Room 10435, 2213 Garland Avenue, Nashville, TN 37232-2733, USA.

E-mail: ki.t.nam@vanderbilt.edu

Received 8 November 2011; revised 25 January 2012; accepted 10 February 2012
} 
I and II. ${ }^{4}$ Ligands in this family include three mammalian TGF- $\beta$ s, activins and bone morphogenetic proteins (BMPs). Pathway-specific Smads consist of Smads 1,5 and 8 that mediate BMP signaling, and Smads 2 and 3 that mediate TGF- $\beta$ and activin signaling. ${ }^{5}$ Activated Smad 2 and Smad3 form a heteromeric complex in the cytoplasm with the common mediator, Smad4, and this complex translocates into the nucleus to activate transcription of various target genes. ${ }^{6}$ Every component of the TGF- $\beta$ signaling pathway can be altered in cancer, including TGF- $\beta$ receptors, Smads and Smad target genes. Defects in the targets of the TGF- $\beta$ signal transduction pathway are observed in many gastrointestinal tumors. ${ }^{7,8}$ The loss of expression of TGF- $\beta$ receptor type II in association with resistance to the growth inhibitory effect of TGF- $\beta$ has been reported in both gastric ${ }^{9}$ and colon cancer. ${ }^{10}$

In human gastric cancer, no mutations in the Smad2 gene have been reported, ${ }^{11}$ but loss of Smad4 was frequently found in gastric cancer. In the setting of gastric carcinogenesis, loss of Smad4 expression is frequently observed and correlated with poor clinical outcome. ${ }^{12-14}$ Consistent with this, the haploid loss of Smad4 initiates gastric carcinogenesis in mice. ${ }^{15}$ In addition, reduced Smad4 expression is observed more frequently in diffuse-type than in intestinal-type gastric carcinomas. ${ }^{13}$ Although Smads 4 and 2 have tumor suppressor activities, Smad3 may also contribute to the oncogenic activities of TGF- $\beta .^{16}$ It remains controversial whether Smad3 functions as a tumor suppressor. However, a recent study showed that expression of Smad3 was suppressed in a subset of human gastric cancers and human gastric cell lines, most likely due to aberrant expression of Smad3 inhibitors. ${ }^{7}$ Smad3-deficient mice have been generated in different laboratories with different strategies. In colon cancer, these mice have a variable phenotype depending on the genetic background and/or on environmental factors associated with animal husbandry. ${ }^{17}$ One group has shown $100 \%$ penetrance of invasive colon carcinoma, ${ }^{18}$ whereas other groups have shown no malignancies. ${ }^{19,20}$

Although the genes encoding TGF- $\beta$ recepters and Smads are genetically altered in certain human cancers, until now no report has considered the role of Smad3 in the early stages of gastric carcinogenesis in mice. We have now examined whether the loss of Smad3 promotes gastric cancer in mice. In this study, we found that Smad3-null mice develop progressive and invasive gastric tumors that arise from the junction between forestomach and glandular epithelium along the lesser curvature. These lesions exhibit the expansion of doublecortin and $\mathrm{Ca}^{2+} /$ calmodulin-dependent kinase-like-1 (DCLK1)expressing tuft cells throughout tumors in the proximal stomach. These findings suggest that Smad3-null mice represent a novel model of fundic gastric tumorigenesis.

\section{MATERIALS AND METHODS}

\section{Mice}

The Smad $3^{+/-}$mice were mated with heterozygous partners to obtain knockout and wild-type littermate control mice for these studies. Mice were maintained on the B6;129/S background under specific pathogen-free conditions in individual, sterile microisolator cages in non-barrier mouse rooms. B6;129/S mice were obtained from Jackson Laboratories (Bar Harbor, ME, USA). During the experiments, the mice were maintained with regular mouse chow and water ad libitum in a temperature-controlled room under a 12-h light/ dark cycle. The care, maintenance and treatment of animals in these studies followed protocols approved by the Institutional Animal Care and Use Committee of Vanderbilt University.

\section{Histopathological Examination}

Immediately after killing, mouse stomachs were opened along the greater curvature. The excised stomachs were fixed in $4 \%$ paraformaldehyde and cut into approximately six strips, processed by standard methods, embedded in paraffin, sectioned at $5 \mu \mathrm{m}$, and stained with hematoxylin and eosin.

\section{Immunohistochemistry}

We carried out immunohistochemistry according to manufacturer's recommendations, typically using a modified citric acid unmasking protocol followed by standard detection with 3, 3'-diaminobenzidine (DAB) or alkaline phosphatase using a kit from Vector Laboratories. Samples were counter-stained with hematoxylin. In some cases, secondary antibodies were conjugated to AlexaFluor 488 (Invitrogen, Camarillo, CA, USA) or Cy-3 and nuclei were counterstained with $4^{\prime}$, 6diamidino-2-phenylindole. We used the following primary antibodies: mouse IgM anti-TFF2/SP (1:250, Abcam, Cambridge, MA, USA), rabbit IgG anti-HE4 (1:1000, Abcam), mouse IgG anti-E-cahderin (1:800, BD Transduction, San Diego, CA, USA), rabbit IgG anti-phosphoSTAT1, rabbit IgG anti-phosphoSTAT3 (1:50, Cell signaling, Danvers, MA, USA), rabbit IgG anti-phosphoSTAT6 (1:1000, Abcam), rat IgG anti- Ki-67 (1:50, Dako, Carpinteria, CA, USA), rabbit IgG anti-DCLK1 (1:500, Abgent, San Diego, CA, USA), mouse IgG anti- Chromogranin A (1:25, AbD Serotec, Raleigh, NC, USA), rabbit IgG anti- $\alpha$-gustducin (1:5000, Santa Cruz, Santa Cruz, CA, USA), mouse IgG anti-Acetylated$\alpha$-tubulin (1:10 000, Sigma, St Louis, MO, USA). The number of DCLK1-positive cells was analyzed in all strips of each stomach. Using an Ariol SL-50 slide scanner imaging system (Genetix, San Jose, CA, USA; Vanderbilt Epithelial Biology Center Shared Resource) and light microscopy $(\times 200)$, we examined 6-month-old Smad $3^{-1-}$ mice (mucosal length of $37200 \mu \mathrm{m}$ ), 10-month-old Smad3 ${ }^{-1-}$ mice (mucosal length of $43400 \mu \mathrm{m}$ ) and wild-type mice (mucosal length of $62000 \mu \mathrm{m}$ ) to determine positive cells in the oxyntic mucosa.

\section{Cell Culture}

The human gastric cancer cell lines AGS and MKN28 (American Type Culture Collection, ATCC, Manassas, VA, USA) were maintained in DMEM media supplemented with $10 \%$ fetal bovine serum at $5 \% \mathrm{CO}_{2}$. 


\section{Smad3 Stable Knockdown Cells Using Lentiviral Short Hairpin RNA}

Five premade lentiviral Smad3 short hairpin RNA (shRNA) constructs and a negative control construct that was created in the same vector system (pLKO.1) were purchased from Open Biosystems (Huntsville, AL, USA). Lentiviral helper plasmids (pCMV-dR8.2 dvpr and pCMV-VSV-G) were obtained from Addgene (Cambridge, MA, USA). Transient lentivirus stocks were prepared following the manufacturer's protocol in 293T cells. MKN28 and AGS cells that were stably expressing shRNA constructs were selected with $0.5-2 \mu \mathrm{g} / \mathrm{ml}$ of puromycin $48 \mathrm{~h}$ after lentivirus infection. After 2 weeks of selection, monolayers of stably infected pooled clones were harvested for use and cryopreserved.

\section{Western Blotting}

Proteins were transferred to a nitrocellulose membrane and blots were probed with the primary antibodies: rabbit anti-Smad3 (Abcam); rabbit anti-phosphorylated STAT3 (phospho-Tyr ${ }^{705}$ ); rabbit anti-STAT3 (Cell Signaling); mouse anti-beta-actin (Abcam) followed by incubation with horseradish-peroxidase-conjugated secondary antibodies and detection with supersignal substrate (Pierce).

\section{Statistics}

The data were analyzed with the JMP software package (version 4.0; SAS Institute, Cary, NC, USA). DCLK1-positive cell numbers were compared by analysis of variance followed by post hoc analysis of significant means by the Dunnett's test. For all comparisons, $P$ values less than 0.05 were considered statistically significant.

\section{RESULT}

Smad3 ${ }^{-1-}$ Mice Exhibit Progressive Gastric Gland Metaplasia and Invasive Gastric Neoplasia that Arises from the Forestomach/Glandular Junction Along the Lesser Curvature

Although the genes encoding TGF- $\beta$ receptors and Smads are genetically altered in certain human cancers, until now, no report has considered the role of Smad3 in the early stages of gastric carcinogenesis in mice. To examine the effects of Smad3 deficiency, we evaluated the stomachs of $\operatorname{Smad} 3^{-1-}$ mice at 4 , 6 and 10 months of age compared with age-matched Smad3 heterozygous and wild-type (WT) mice. None of the Smad $3^{-1-}$ mice on the B6;129/S background showed any significant gross anatomical or pathological abnormalities in the stomach at 4 months of age (data not shown). Examination of Smad $3^{-1-}$ mouse $(n=6)$ stomachs at 6 months of age revealed the presence of grossly whitish exophytic growths in the limiting ridge along the lesser curvature in all of the mice, whereas stomachs from Smad3 heterozygote $(n=7)$ and WT mice $(n=5)$ exhibited normal gastric morphology (Figure 1a). Histologically, all 6-month-old Smad $3^{-1-}$ mouse stomachs showed metaplastic columnar glands initiated from the transition zone at the junction between the forestomach and the glandular epithelium along the lesser curvature of the stomach (Figure $1 \mathrm{~b}$ and $\mathrm{c}$ ). However, both the greater curvature of $\mathrm{Smad}^{-1-}$ mice and lesser curvature of $\mathrm{Smad}^{+/-}$mice showed a normal histological appearance in the transition zone junction between the squamous forestomach and the glandular epithelium (Figure $1 \mathrm{~b}$ and $\mathrm{d}$ ). These initial metaplastic changes in the gastric mucosa of Smad3-null mice were analyzed by immunohistochemistry staining for TFF2/SP, which is a marker of SPEM (spasmolytic polypetide-expressing metaplasia). In glands within the fundic mucosa adjacent to the forestomach, TFF2/SP-immunoreactive mucous cells were present in metaplastic glands that showed branching at their bases (Figure 1e and $\mathrm{f}$ ).

To investigate the progression of initial gastric gland metaplasia in the junction, a total of seven 10 month-old $\mathrm{Smad}^{-1-}$ mice and five Smad3 $3^{+1+}$ mice were examined histologically. Although the greater curvature of 10-monthold Smad $3^{-l-}$ mice showed normal gastric morphology, the lesser curvature exhibited neoplastic progression showing metaplastic fundic glands expanding out towards the antrum from the forestomach/glandular junction $(n=7)$ (Figure 2a). In glands within the fundic mucosa adjacent to the forestomach, some areas of high-grade dysplasia arising under the junction were observed (Figure 2a Box and b). The dysplastic cells showing prominent nuclear pleomorphism and disorganization expanded from the junction into the fundic mucosa, where they replaced the normal foveolar cells and fundic glands (Figure 2b). Interestingly, we observed the presence of numerous cystic structures within the submucosa of the gastric wall (Figure 2a arrows, $c$ and d). The glands abnormally invading within the muscle of the gastric wall were lined by well-differentiated metaplastic epithelial cells containing basal nuclei forming multiply extended glandular formations (Figure 2d). The gastric mucosa of Smad3 $3^{-1-}$ mice exhibited areas of metaplasia with prominent TFF2/SP expression, including in epithelial cells lining cysts invading into the gastric wall (Figure 2e and f). We did not observe any other normal differentiated gastric lineages in these areas, including surface mucous cells, parietal cells and chief cells (data not shown). We also analyzed these metaplastic changes in TFF2/SP-positive epithelial cells lining cysts invading into the gastric wall by immunostaining for human epididymis 4 (HE4/WFDC2), which is not present in the normal stomach, but is strongly expressed in SPEM. ${ }^{21}$ We observed strong HE4 expression in the cysts invading into the gastric wall (Figure 2g). These results support the concept that gastritis cystica profunda is a manifestation of an ongoing metaplastic process in the Smad3-deficient mice.

\section{Increased Expression of Oncogenic Markers in the Gastric Mucosa of Smad3 ${ }^{-1-}$ Mice}

We next sought to examine whether oncogenic markers were expressed in gastric tumor cells in $S \mathrm{mad} 3^{-1-}$ mice. To investigate the characteristics of the tumor in $\mathrm{Smad}^{-1-}$ mice, we immunostained gastric tissue for markers associated with 

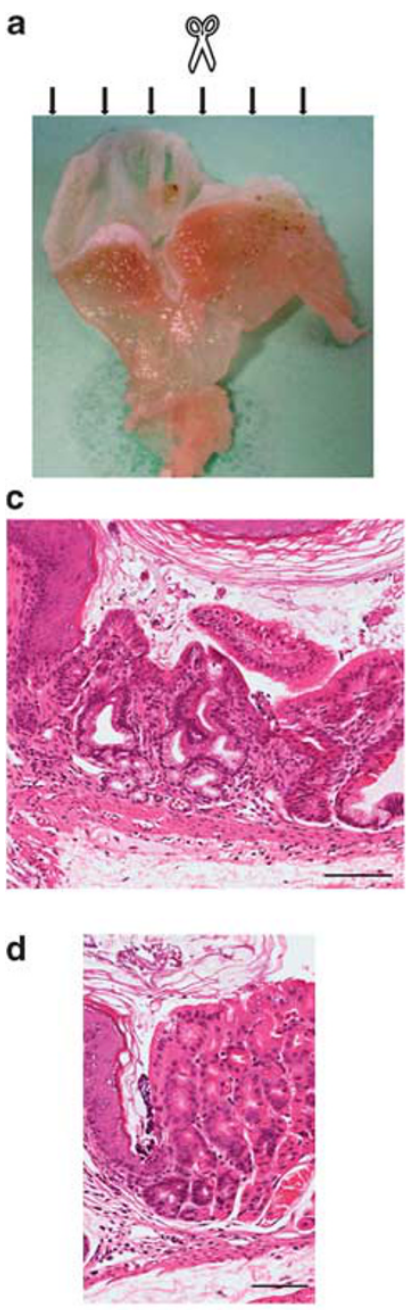

b
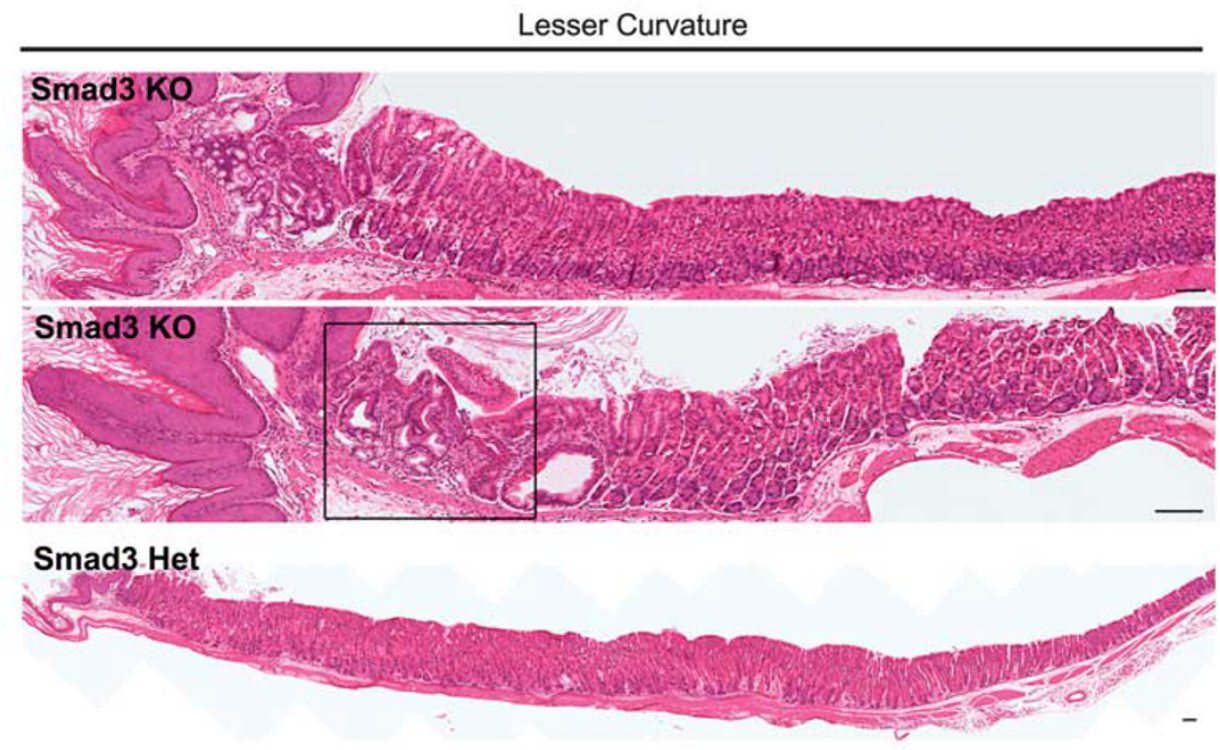

Greater Curvature e

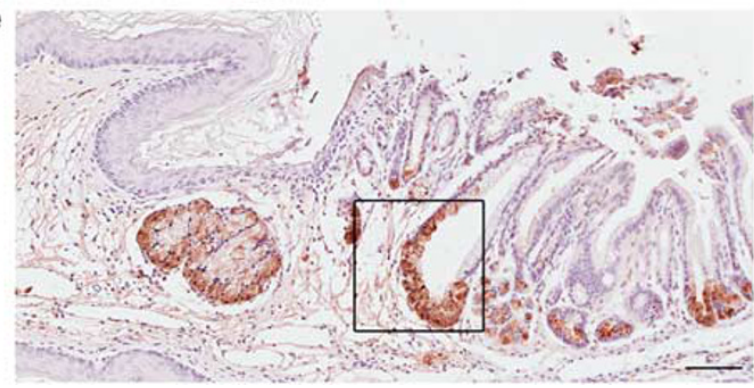

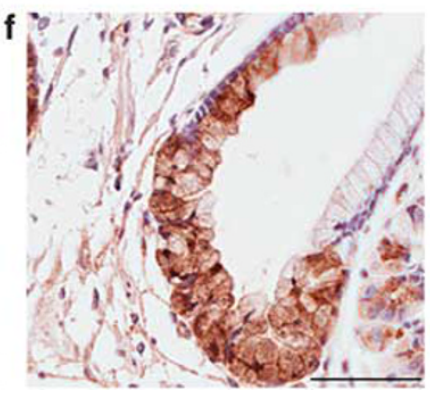

Figure 1 Initiation of gastric tumor in 6-month-old Smad3 ${ }^{-1-}$ mice. (a) Gross appearance of the stomach from a 6-month-old Smad3-deficient mouse. Note the irregular whitish cauliflower-like growths in the limiting ridge along the lesser curvature. Filled multiple arrows correspond to the locations of sections in panel b. (b) H\&E staining of the stomach of a 6-month-old Smad3-deficient mouse. Although the greater curvature of Smad3 ${ }^{-1-}$ mice (KO) and lesser curvature of Smad3 $3^{+/-}$(Het) mice showed normal histological appearance in transition zone junction between the forestomach and the glandular epithelium (b and $\mathbf{d}$ ), in $\mathrm{Smad}^{-1-}$ mice (KO) mucosal metaplasia extended from the lesser curvature in panlels $\mathbf{b}$ and $\mathbf{c}$. (c) Higher magnification of the lesser curvature of Smad3 $3^{-1-}$ mouse section in panel $\mathbf{b}(\mathrm{KO})$. (d) Higher magnification of the greater curvature of Smad $3^{-1-}$ mouse section in panel $\mathbf{b}$ (KO). panel e TFF2/SP staining of metaplastic glands initiated from the first fundic gland at the junction between the forestomach and the glandular epithelium. (f) Higher magnification of panel e. Bar size, $50 \mu \mathrm{m}$.

neoplastic transformation with antibodies against Ki-67, E-cadherin and STATs. Ki-67 antigen is a cell cycle related nuclear protein commonly used as a proliferation marker in proliferating and neoplastic tissues, including the stomach. In cells throughout the metaplastic fundic glands, including cystically dilated glands invading into submucosa as well as gastric epithelial glands within the muscle layers of gastric wall, we detected proliferating cells by Ki-67 staining (Figure $3 \mathrm{a}$ and $\mathrm{b}$ ). 
a

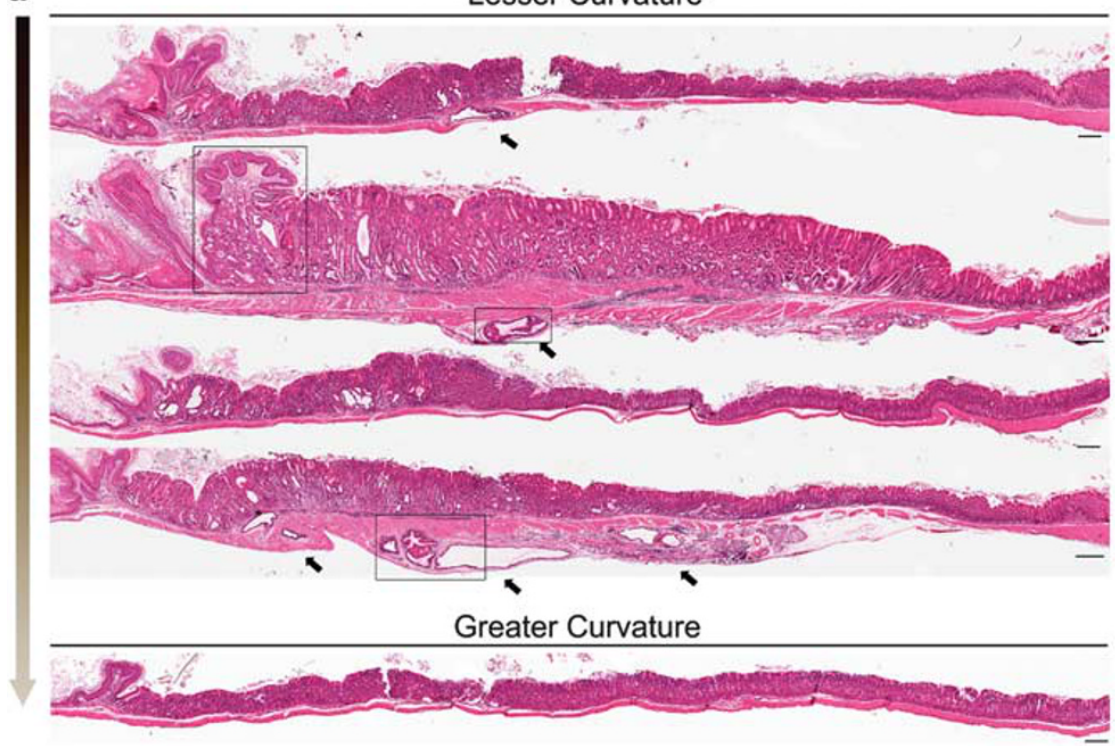

e

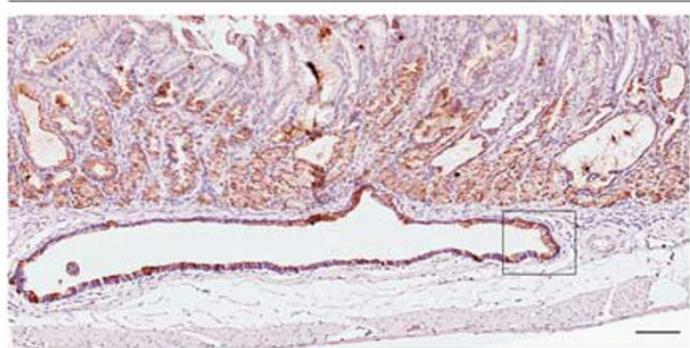

TFF2/SP

Lesser Curvature

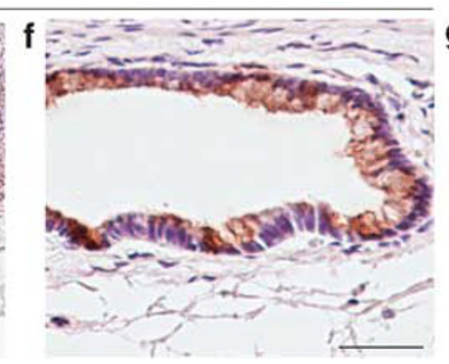

b

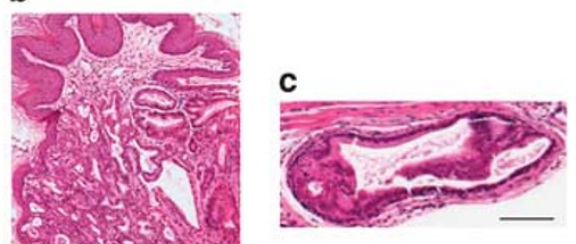

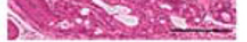

d

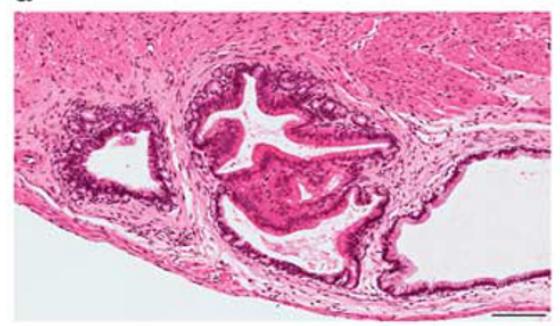

HE4

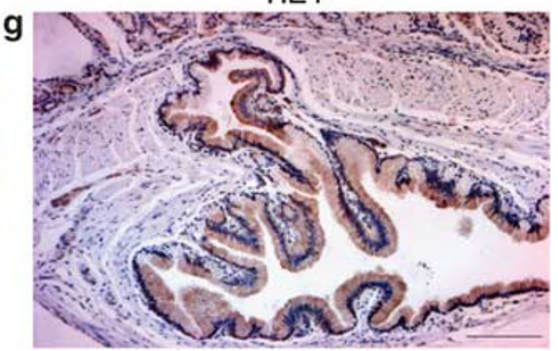

Figure 2 Progression of gastric tumor and invasion in 10-month-old Smad3 $3^{-1-}$ mice. (a) H\&E staining shows the lesser curvature with neoplastic progression and metaplastic fundic glands expanding out towards the antrum from the forestomach/glandular junction. Note the presence of numerous cystic structures within the submucosa of the gastric wall (arrows). However, the greater curvature showed normal gastric morphology. Filled dark brown arrow (left side) indicates the arrangement of sections from the lesser curvature to the greater curvature. (b) Higher magnification of lesser curvature in panel a. The dysplastic cells showing prominent nuclear pleomorphism and disorganization. (c) Higher magnification of invasive glands in the muscle wall from panel a, second section. (d) Higher magnification of invasive glands in muscle wall from panel panel a, fourth section. (e) TFF2/SP expression in metaplastic glands and in epithelial cells lining cysts within the invasive region of the gastric wall. (f) Higher magnification of panel e. (g) HE4 expression in TFF2/SP-positive epithelial cells lining cysts within the invasive region of the gastric wall. Bar size, $100 \mu \mathrm{m}$.

Nevertheless, some regions of gastric epithelial cells within cysts penetrating through the muscle of the gastric wall showed no expression of Ki-67 (Figure 3c).

E-cadherin is a cell adhesion molecule that is essential to maintain the integrity of cell-cell contact in epithelial cell layers, and aberrant expression of E-cadherin is associated with gastric cancer histological subtypes. ${ }^{22,23}$ There is general agreement that the absence or reduction of E-cadherin expression occurs more frequently in diffuse gastric cancer than in the intestinal type cancers. Membrane-localized E-cadherin was detected in metaplastic glands cells within the mucosa, but we observed numerous cells containing aberrant cytosolic staining in papillary glands invading into the submucosa (Figure 3d). Nevertheless, we did not observe any significant relocation of $\beta$-catenin from the junctions to the cytosol or nucleus (data not shown).

As inflammatory cells and their interactions with epithelial cells may be involved in carcinogenesis, we examined STAT proteins as central regulators of immune responses in the tumor microenvironment. Signaling by various STATs have an essential role in inflammation and cancer. To investigate the activation of the STAT family in invasive tumor tissues of $\mathrm{Smad}^{-I-}$ mice, we examined whether STAT1, STAT3 and STAT6 were phosphorylated and activated in epithelial cells in Smad3-null mice. The activated phosphorylated form of STAT3, phosphoSTAT3, was observed in the gastric epithelial cells just above invading glands within the muscle layer (Figure 3e), but staining for phosphoSTAT1 and phosphoSTAT6 was not observed (data not shown). Nevertheless, no phosphoSTAT3 staining was present in the invading tumor cells.

\section{Depletion of Smad3 Protein in AGS and MKN28 Gastric Cancer Cells Leads to Increased Phosphorylated form of STAT3}

Considering our findings that metaplastic cells in Smad3-null mice exhibited the activated phosphorylated form of STAT3, 

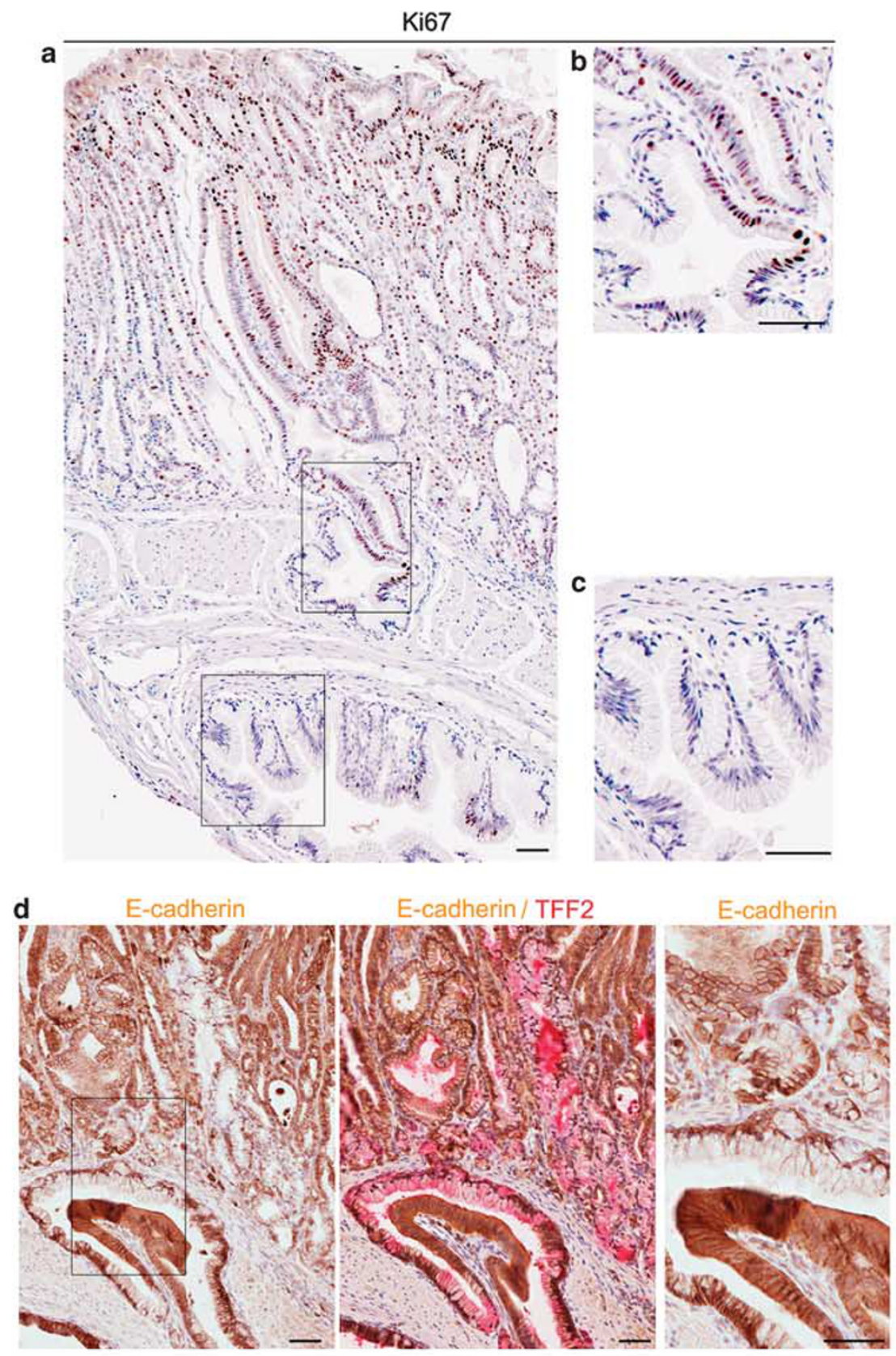

e

phosphoSTAT3

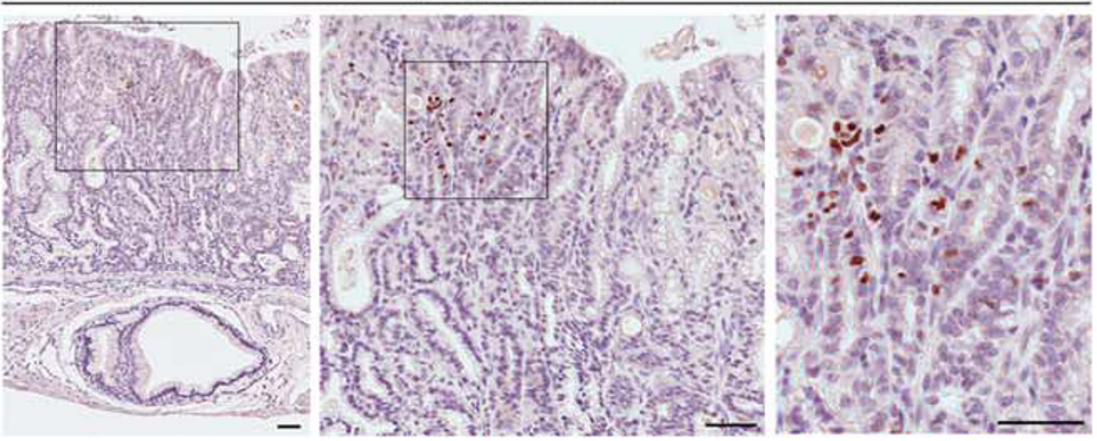


phosphoSTAT3, we sought to determine whether loss of Smad3 expression directly affects STAT3 activation. We used Smad $3^{\text {shRNA }}$ lentivirus and puromycin to select for stable pools of AGS and MKN28 cells with Smad3 depletion along with control lines with pLKO.1. When stable cell pools were analyzed for Smad3 protein expression by immunoblot, we found that Smad3 protein expression was significantly suppressed in the two cell lines selected with Smad $3^{\text {shRNA }}$ lentivirus, but not with the control pLKO.1 virus (Figure 4, first lane). Although Smad3 knockdown had no effect on STAT3 expression in both AGS and MKN28 cell lines, phosphoSTAT3 was prominently increased in Smad3 knockdown cell lines (Figure 4). These results indicate that loss of Smad3 expression can lead directly to increased STAT3 phosphorylation.

\section{DCLK1-Positive Cells are Expanded in Gastric Tumors Arising from the Junction in Smad3 ${ }^{-l-}$ Mice}

Tumorigenesis is thought to arise specifically from resident mucosal stem cell populations. Recently, DCLK1 was identified as a putative quiescent intestinal stem cell marker in the intestinal crypt. $^{24}$ Therefore, we investigated whether DCLK1-positive cells were also expressed in stomach mucosa. In the normal fundus of wild-type mice, a few DCLK1-positive cells were located in the neck-isthmus region of the glandular unit, in the same area where normal stem/progenitor cells reside (Figure 5a, center). In the antrum, a few scattered DCLK1-positive cells were located in middle of antral glands (Figure 5a, right). Interestingly, long spindle shaped DCLK1-positive cells were present in the first fundic gland at the transition between the forestomach and the glandular epithelium (Figure 5a, left). Owing to the location of DCLK1-positive cells at the junction between the forestomach and the glandular epithelium, we investigated whether the DCLK1-positive cells were present at the sites of tumor initiation in the transition zone junction between the forestomach and the glandular epithelium in $\mathrm{Smad} 3^{-1-}$ mice. We observed a prominent expansion of DCLK1-positive cells in the junction between the forestomach and the glandular epithelium in Smad3 ${ }^{-1-}$ mice (Figure $5 b$ ). In the middle of developed tumors, DCLK1-positive cells represented a large component in metaplastic glands including in the area of initiated invasion (Figure 5c). In invading epithelial glands within muscle wall, DCLK1-positive cells were present throughout the cystic gland epithelium. The DCLK1-labeled cells had projections to the gland lumen (Figure 5d). However, we did not observe any increase in DCLK1-expressing cells in the antrum of 10 -month-old $\mathrm{Smad}^{-1-}$ mice (Figure 5e).

\section{DCLK1-Positive Cells do not Express Biomarkers Associated with other Differentiated Lineages in Smad3 $^{-1-}$ Mice Tumor}

To investigate whether DCLK1-positive cells colocalized with SPEM, we conducted dual immunostaining for DCLK1 and TFF2/SP in a tumor area including areas with invasion. DCLK1-positive cells did not co-stain with TFF2/SP in any region of tumor including invading epithelial glands within the muscle wall (Figure $6 \mathrm{a}$ and $\mathrm{d}$ ). To determine whether DCLK1-positive cells expressed with progenitor cell or enteroendocrine markers, we performed double-label immunofluorescence staining for DCLK1 with Ki-67 and chromogranin A, respectively. There was no co-localization observed for any of the markers tested (Figure $6 \mathrm{~b}$ and $\mathrm{c}$ ). These data suggest that DCLK1 marks a unique cell lineage within the mouse stomach tumor.

\section{DCLK1-Positive Cells in Smad3 ${ }^{-1-}$ Mouse Tumors Arising from the Junction Between the Forestomach and the Glandular Epithelium Are Tuft Cells}

Recent studies have suggested that DCLK1 immunoreactivity represents a highly specific and robust marker of post-mitotic, differentiated, tuft cells, a minority cell lineage of the intestinal epithelium, rather than a marker for intestinal epithelial stem cells. ${ }^{25,26}$ Tuft cells are part of the diffuse chemosensory system, found scattered in multiple epithelia including the gastrointestinal tract. ${ }^{27}$ Therefore, we examined

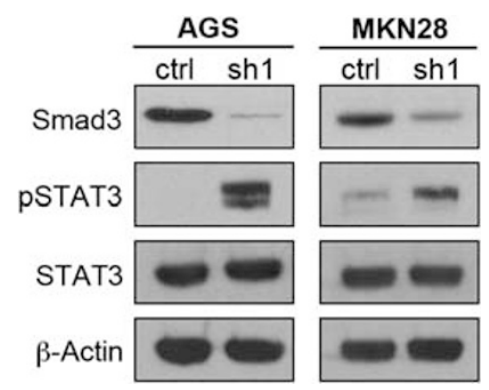

Figure 4 STAT3 and phosphoSTAT3 expression in Smad3 knockdown gastric cancer cell lines. Immunoblot analyses of the Smad3 protein and phospho-STAT3 levels in AGS and MKN28 cells using beta-actin as a loading control. The short hairpin RNA-mediated (ShRNA) knockdown of Smad3 increased the phosphorylated form of STAT3 in both AGS and MKN28 gastric cancer cells.

Figure 3 Oncogenic characteristics in gastric mucosa of Smad3 ${ }^{-1-}$ mice. (a) Ki-67 expression throughout the metaplastic fundic glands, including cysticly dilated glands invading into submucosa as well as gastric epithelial glands within the muscle of the gastric wall. (b) Higher magnification of panel a. (c) Higher magnification of panel a. Some regions of gastric epithelial cells within the muscle of gastric wall showed no expression of Ki-67. (d) E-cadherin expression in metaplastic and invasive region. Note the cytosolic E-cadherin in papillary gland cells within the invading submucosal gland (b). Right panel: higher magnification. Brown: E-cadherin, Red: TFF2/SP. (e) Activated form of STAT3, phosphoSTAT3, expression in gastric epithelial cells just above invading gland within the muscle layer. Right panel: higher magnification. Bar size, $50 \mu \mathrm{m}$. 

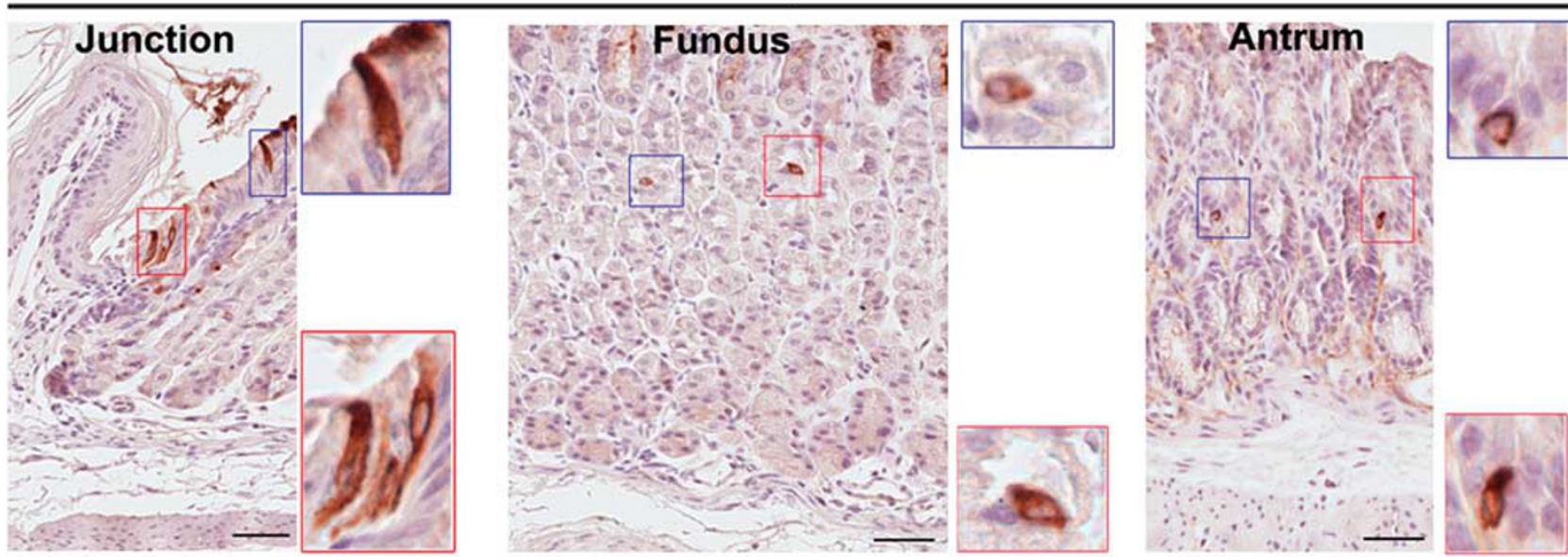

b

Smad 3 \%
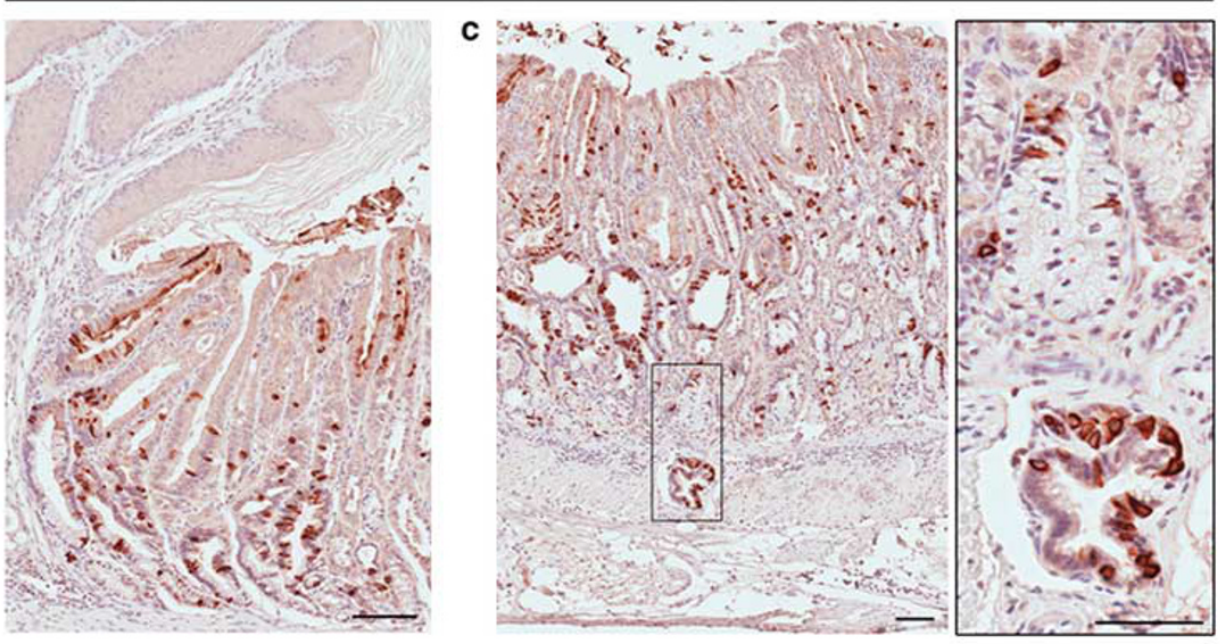

d
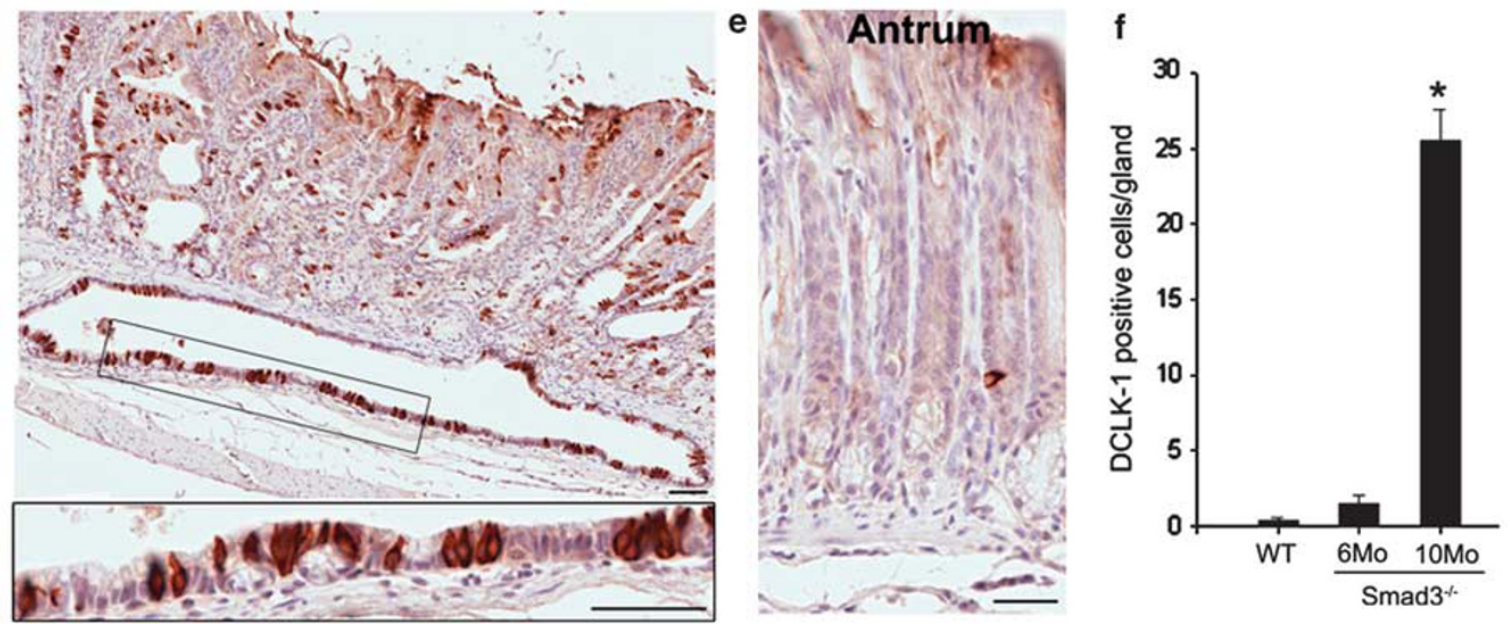

Figure 5 DCLK1 expression in normal wild-type gastric mucosa and Smad3 ${ }^{-1-}$ mouse tumor. (a) DCLK1 expression in normal wild-type mouse. Note the cells present in the first fundic gland in the transition zone junction between the forestomach and the glandular epithelium (Junction), Fundus and Antrum. Each right hand panel: Higher magnification of DCLK1-positive cells (b-e) DCLK1 expression in Smad3 ${ }^{-1-}$ mouse tumor. (b) DCLK1 staining cells in the transition zone junction between the forestomach and the glandular epithelium. (c) The middle of developed tumor in a section including the area of initiated invasion. Right panel: higher magnification of tumor region. (d) Invading epithelial gland within muscle wall. Bottom panel: higher magnification. Note DCLK1-positive cells with projections that contact the cystic gland lumen. (e) Antrum of Smad3 $3^{-1-}$ mouse tumor. There was no change in DCLK1expressing cells. (f) The quantitation of DCLK1-positive cells in wild-type and Smad3 $3^{-1-}$ mice $\left({ }^{\star} P<0.01\right.$ compared with wild-type mice). Bar size, $50 \mu \mathrm{m}$. 


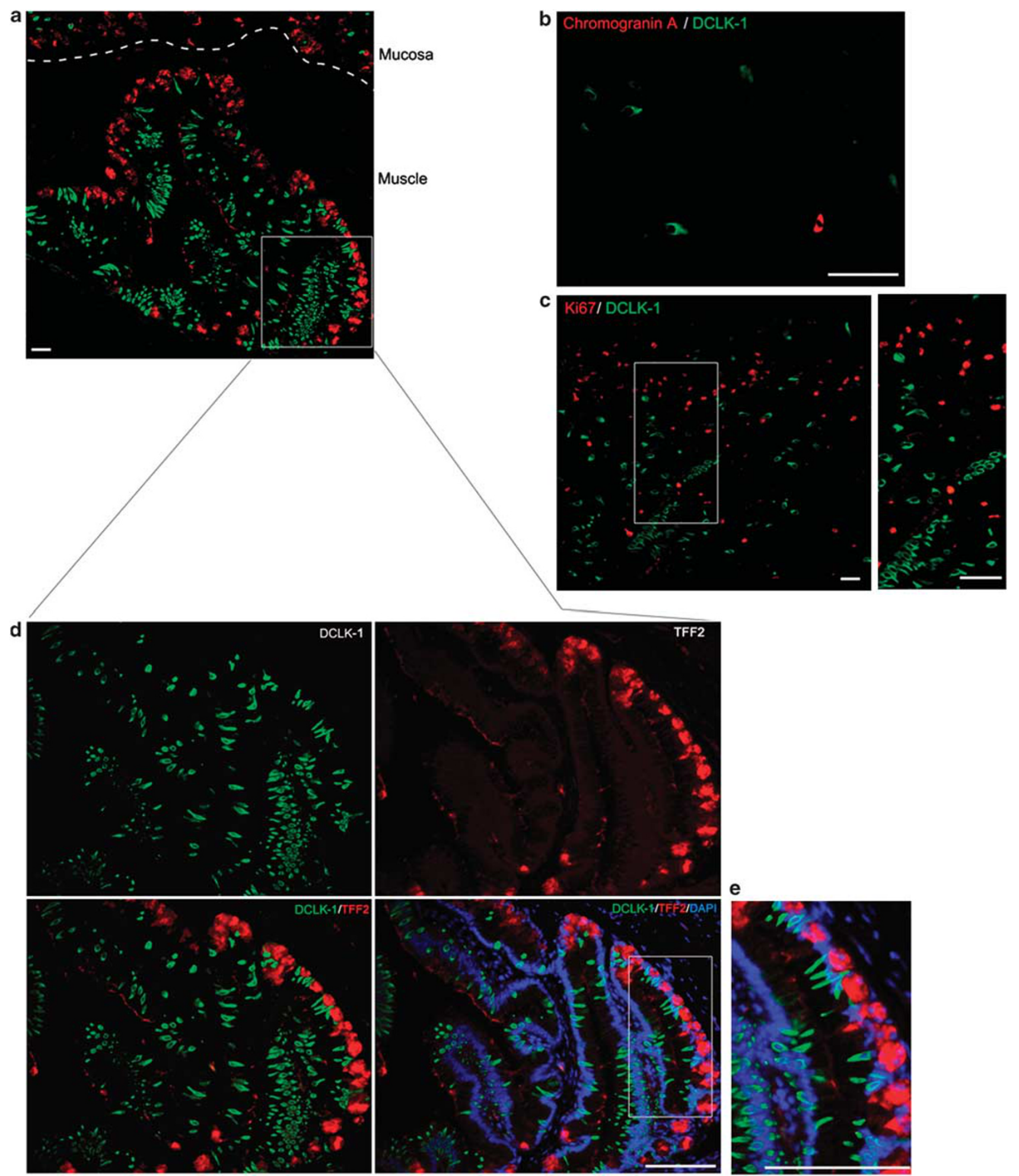

Figure 6 DCLK1-positive cells do not express biomarkers associated with differentiated lineages in Smad3 ${ }^{-1-}$ mice tumor. (a) Double immunostaining for DCLK1 and TFF2/SP. DCLK1-positive cells did not colocalized with TFF2/SP in any other region of tumor including invading epithelial gland within muscle wall (d). (b) Double immunostaining for DCLK1 and chromogranin A. DCLK1-positive cells did not colocalized with chromogranin (a). (c) Double immunostaining for DCLK1 and Ki-67. DCLK1-positive cells did not colocalized with Ki-67. Right hand panel: higher magnification. (d) Higher magnification of panel a. (e) Higher magnification of panel d. Bar size, $50 \mu \mathrm{m}$. 


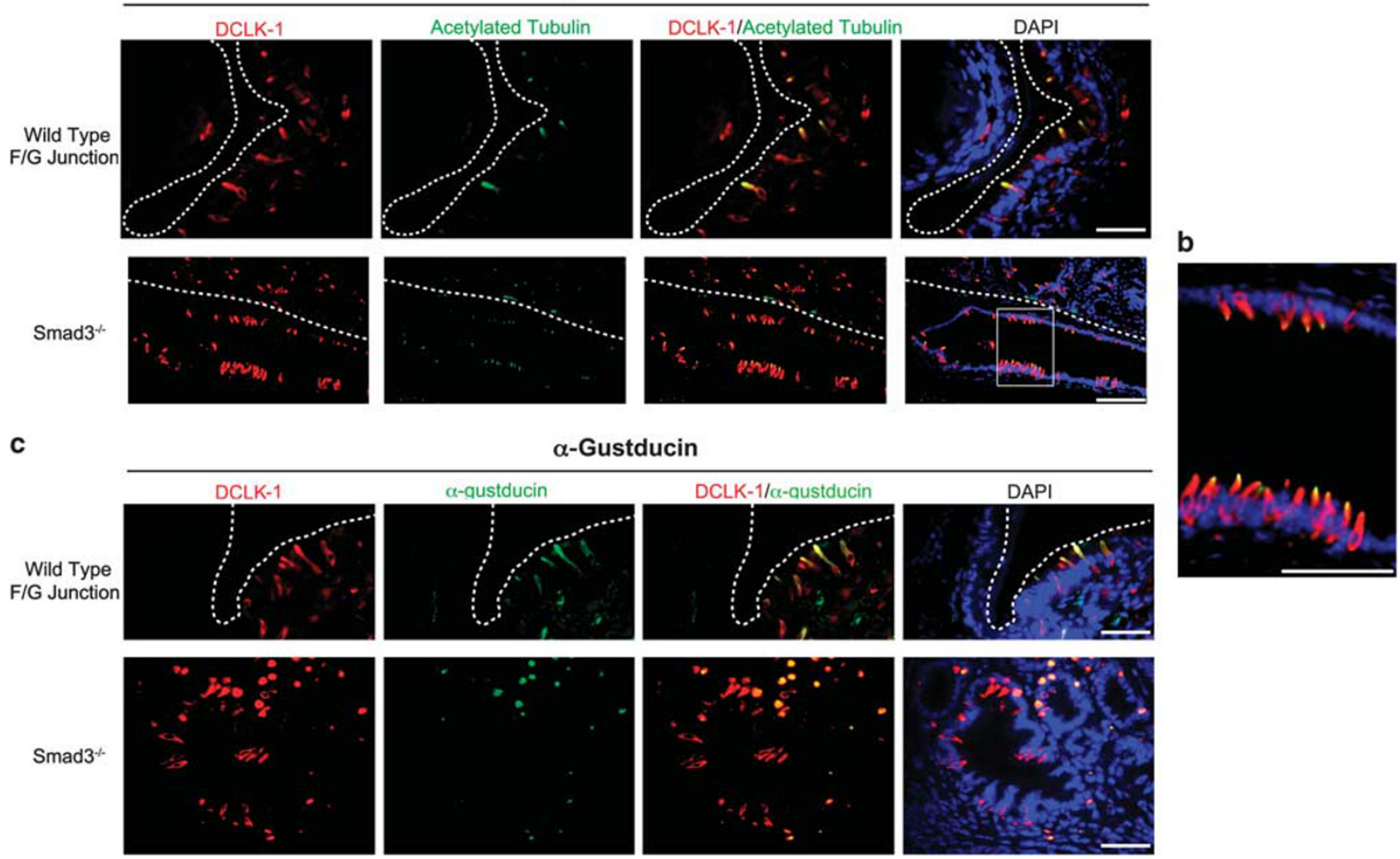

Figure 7 DCLK1-positive cells express tuft cell markers. (a) Double immunostaining for DCLK1 (red) and acetylated- $\alpha$-tubulin (green). Upper panel: transition zone at the junction of the forestomach and the glandular epithelium (F/G) in normal wild-type mouse, dashed line; gastric lumen boundary. Bottom panel: Smad3 $3^{-1-}$ mouse tumor, dashed line: muscle layer boundary. (b) Higher magnification of panel a. (c) Double immunostaining for DCLK1 (red) and $\alpha$-gustducin (green). Upper panel: transition zone at the junction of the forestomach and the glandular epithelium (F/G) in a normal wild-type mouse, dashed line: gastric lumen boundary. Bottom panel: Smad $3^{-1-}$ mouse tumor. Bar size, $50 \mu \mathrm{m}$.

whether the markers of the tuft cell identify the prominent DCLK1-positive cell lineage found in $\mathrm{Smad}^{-1-}$ mouse tumors arising from the junction between the forestomach and the glandular epithelium. To visualize the complex microtubule bundles present at the apical surface of tuft cells, we performed double-label immunofluorescence staining for DCLK1 with acetylated- $\alpha$-tubulin in both normal stomach and tumor developed in Smad3 $3^{-1-}$ mice. In the normal stomach at the junction between the forestomach and glandular epithelium, DCLK1-positive cells colocalized with acetylated- $\alpha$-tubulin in the apical region of cell. In tumors of $\mathrm{Smad}^{-1-}$ mice, including invasive glandular lesions within the muscle wall, DCLK1-positive cells colocalized with acetylated- $\alpha$-tubulin in the apical region of cell. These double-positive microtubule-rich sensory cilia labeled with DCLK1 and acetylated- $\alpha$-tubulin in the apical regions of cells protruding into the lumen (Figure $7 \mathrm{a}$ and $\mathrm{b}$ ).

Tuft cells of the mouse stomach express $\alpha$-gustducin, a heterotrimeric GTP-binding protein $\alpha$-subunit that is implicated in sweet and bitter taste signal transduction, ${ }^{28}$ in cells scattered throughout the fundic mucosa. ${ }^{29,30}$ In addition, previous investigations have noted that a remarkably high number of $\alpha$-gustducin-positive cells are clustered within the first gland of the fundic mucosa underneath the tissue fold of the so-called 'limiting ridge. ${ }^{29}$ We therefore sought to determine whether the cells expressing DCLK1 also expressed $\alpha$-gustducin in $\operatorname{Smad} 3^{-1-}$ mice tumors initiated from the junction between the forestomach and the glandular epithelium. We performed double-labeled immunofluorescence staining for DCLK1 with $\alpha$-gustducin in both normal stomach and tumor developed in Smad $3^{-/-}$mice. In wild-type mice, in the first gland at the junction between the forestomach and glandular epithelium, some of DCLK1positive cells colocalized with $\alpha$-gustducin. In the tumors of Smad $3^{-l-}$ mice, only a few of the DCLK1-positive cells colocalized with $\alpha$-gustducin. These double positive cells were located within metaplastic glands and formed extensions to the gland lumen (Figure 7c). The vast majority of the DCLK1 cells did not express $\alpha$-gustducin. These results indicate that while the DCLK-1-expressing cells are tuft cells, there may be subspecialization amongst these sensory cells in terms of the taste receptors that they express.

\section{DISCUSSION}

The Smad3-null mouse model represents a unique model of gastric neoplasia arising in the proximal fundic mucosa. 
Previous investigations have focused attention on models of gastric neoplasia that localize either to the fundic mucosa in general or to the antrum. Mice infected with either $H$. felis or H. pylori develop metaplastic and dysplastic changes in the acid-secreting fundic mucosa. ${ }^{31-34}$ Similarly, models of acute parietal cell loss elicit metaplastic changes in the fundus. ${ }^{35,36}$ Similar results are also seen in $H$. pylori-infected Mongolian gerbils. ${ }^{37}$ In contrast, several genetic models, including TFF1 null, gastrin null and gp130-mutant mice, develop gastric dysplasia and neoplasia confined to the antrum. ${ }^{38-40}$ The Smad3 null mouse model described in the present studies shows development of a distinctly proximal fundic dysplastic lesion that appears to arise from the first gland of the fundic mucosa along the lesser curvature of the stomach at the junction between the squamous forestomach and the glandular epithelium. These studies therefore reveal a process of neoplasia that is uniquely referable to the proximal stomach.

Smad3 is an intracellular transducer of TGF- $\beta$ signals. Functionally significant mutations in Smad2 have been detected in some human sporadic colorectal cancers, ${ }^{41}$ but were not detected in gastric cancer. ${ }^{11}$ Despite the close sequence similarity between Smad2 and Smad3, mutations in the Smad3 gene have not been reported in human colorectal cancer. ${ }^{42}$ However, recent investigations have indicated that the expression of $\operatorname{Smad} 3$ was suppressed in a subset of human gastric cancers and human gastric cell lines, most likely because of aberrant expression of Smad3 inhibitors. ${ }^{7}$ Moreover, the re-expression of $\operatorname{Smad} 3$ in Smad3-deficient gastric cancer cells restored TGF- $\beta$ signaling and induced a tumor suppressive activity. ${ }^{7}$ Smad2 and Smad3 differ in their effect on mouse tumorigenesis. Homozygous Smad2-null mice are embryonic lethal, whereas heterozygous Smad2 mice show no evidence of tumor development. ${ }^{43,44}$ However, homozygous Smad3null mice are viable and develop a low multiplicity of invasive colonic adenocarcinomas in the $129 / \mathrm{Sv}$ background. ${ }^{18}$ We have found that Smad3-null mice in the B6;129/S background develop progressive and invasive gastric tumors initiated from the junction between forestomach and glandular epithelium along the lesser curvature. No previous report has indicated the presence of the gastric tumors in Smad3-null mice except in a notation on the Jackson Laboratory (Bar Harbor, ME) website (http:// jaxmice.jax.org/strain/003451.html). Although the gastric tumors develop in this strain at 4-6 months age at the Jackson Laboratory and in our colony, colorectal adenocarcinomas were not observed at the Jackson Laboratory facility. To develop the colon cancer in Smad3-deficient mice, Helicobacter hepaticus infection is required. ${ }^{45}$ While colon cancer phenotypes did not developed in Smad3-null mice on the 129/Sv background maintained in a Helicobacter-free environment for up to 9 months, infection of the same mice with Helicobacter triggered colon cancer in $50-66 \%$ of the mice. ${ }^{45}$ These results suggested that the original Smad3-null mice might have been infected with Helicobacter hepaticus or other colitis-inducing organisms. ${ }^{18}$ In contrast, the development of spontaneous and invasive gastric tumors in Smad3-deficient mice appears to be independent of Helicobacter infection.

An important finding in our current study is that the gastric tumors in Smad3-null mice developed at the junction between forestomach and glandular epithelium along the lesser curvature. The first gland of the gastric fundus appears to have a unique compendium of lineages. It is devoid of parietal cells and chief cells and contains mucous cells and endocrine and sensory tuft cells. This first gland is present in most, if not all, mammalian species either at the border of the forestomach and glandular fundus as in rodents or at the esophagogastric junction as in humans and rabbits. Previous investigations have suggested that this first glandular unit may have unique regenerative properties. Canfield et al ${ }^{46}$ reported that, while mice-expressing HSV thymidine kinase in parietal cells (H/K-ATPase-thymidine kinase mice) treated with ganciclovir sloughed their entire fundic mucosa, the first gland was protected and re-epithelialization of the fundus was observed emanating from cells migrating out of this first gland remnant. These results suggested that the first glandular unit was isolated from gap junctions responsible for spreading toxic ganciclovir adducts through the fundic mucosal cells. Others have noted that the first glandular unit in the mouse stomach is enriched for cells expressing either Lgr $5^{47}$ or DCLK1, ${ }^{24}$ putative markers of intestinal progenitor cells. Most recently, McKeon and colleagues ${ }^{48}$ have reported that the first glands are a repository of residual embryonic cells in the adult mouse. All of these investigations indicate that the first gland of the fundus may represent a repository for cells capable of rescuing severe mucosal damage in the stomach. Lee and investigators ${ }^{49}$ have emphasized that severe pathology more often develops in regions of the gastric epithelium where there is a marked transition in the census of acid-producing parietal cells. The transitional zones are dynamic rather than static areas. Thus, the prominence of DCLK1-expressing cells in the invasive glands in 10-monthold mice may reflect the origin of the tumors from the cells of this first fundic gland.

Normally, cellular proliferation in the body and fundus of the stomach is restricted to the progenitor zone in the gland isthmus. ${ }^{50}$ Recently, doublecortin and $\mathrm{Ca}^{2+} /$ calmodulindependent kinase-like-1 (DCLK1), a microtubule-associated kinase expressed in postmitotic neurons, has been suggested as a putative quiescent intestinal stem cell marker. Originally this gene was identified as a potential stem cell marker from cDNA libraries prepared from laser capture microdissected small intestinal and gastric epithelial progenitor populations. DCLK1 expression was upregulated in an enriched gastric epithelial progenitor cell population from the fundus. ${ }^{51}$ DCLK1-expressing cells resided in the isthmus region of the stomach glands and did not express biomarkers associated with differentiated lineages. ${ }^{24,51}$ 
However, recent studies have indicated that DCLK1 is expressed in tuft cells. ${ }^{25}$ Tuft cells, also known as brush, caveolated or multivesicular cells, are part of the diffuse chemosensory system, found scattered in multiple epithelia including the gastrointestinal tract. ${ }^{27}$ Their most characteristic morphological features are long and blunt microvilli, which have prominent rootlets and a well developed tubulovesicular system in the supranuclear cytoplasm. ${ }^{27}$ Despite the many morphological studies conducted to date, the functions of tuft cells are still obscure. Immunohistochemical studies demonstrating the presence of $\alpha$-gustducin, the GTP-binding $\alpha$-subunit of a trimeric G protein complex implicated in taste signal transduction, have shed further light on the function of tuft cells. ${ }^{27,52}$ As $\alpha$-gustducin was first described in taste receptor cells of the tongue, ${ }^{53}$ and was subsequently found in tuft cells of the alimentary tract, many investigators now consider these cells as chemoreceptive in nature. Recently, Hass et al ${ }^{29}$ found a large cluster of $\alpha$-gustducin-positive cells located at junction between forestomach and fundic mucosa of the mouse stomach, at the so-called 'limiting ridge'. In our study, DCLK1-positive cells in Smad3 ${ }^{-1-}$ mouse tumors initiated from the junction between the forestomach and the glandular epithelium were immunoreactive for $\alpha$-gustducin. Although the number of DCLK1-positive cells increased in Smad $3^{-l-}$ tumors, only a subset of these were immunoreactive for $\alpha$-gustducin. Nevertheless, the vast majority or all of the DCLK1-positive cells were also immunoreactive for acetylated- $\alpha$-tubulin staining of the complex microtubule bundle at the apical surface. DCLK1/ acetylated- $\alpha$-tubulin dual positive cells were present in the epithelial cells in the tumor and the invasive area developed in Smad $3^{-1-}$ mice. Importantly, we did not observe any colabeling of DCLK1 with either TFF2/SP or Ki-67. These results all indicate that a DCLK1-expressing tuft cell lineages is markedly expanded during the progression of invasive proximal gastric neoplasia in Smad3-deficient mice.

In summary, Smad3-null mice develop gastric tumors in the fundus, which arise at the junction between the forestomach and the glandular epithelium. The tumors appear to develop from the first glandular unit of the fundic mucosa and progress to prominent invasive tumors. Progression to more invasive lesions is accompanied by an expansion of tuft cells marked by DCLK1 expression. These findings suggest that Smad3-null mice represent a novel model of fundic gastric tumor initiated from forestomach/glandular transition zone along the lesser curvature.

\section{ACKNOWLEDGEMENT}

This work was supported by NIH Grant RO1 DK071590 and a VA Merit Review award (to JRG) and NCI CA46413, GI Special Program of Research Excellence (P50 CA95103), and Mouse Models of Human Cancers Consortium (U01 CA084239) to RJC. These studies utilized core facilities supported by the Vanderbilt Ingram Cancer Center (P30 CA68485) and the Vanderbilt Digestive Disease Research Center (DK058404).

\section{DISCLOSURE/CONFLICT OF INTEREST}

The authors declare no conflict of interest.

1. Parkin DM, Bray F, Ferlay J, et al. Global cancer statistics, 2002. CA Cancer J Clin 2005;55:74-108.

2. Camargo MC, Anderson WF, King JB, et al. Divergent trends for gastric cancer incidence by anatomical subsite in US adults. Gut 2011;60: 1644-1649.

3. Goldenring JR, Nam KT. Oxyntic atrophy, metaplasia, and gastric cancer. Prog Mol Biol Transl Sci 2010;96:117-131.

4. Feng $\mathrm{XH}$, Derynck R. Specificity and versatility in TGF-beta signaling through Smads. Annu Rev Cell Dev Biol 2005;21:659-693.

5. Derynck R, Zhang Y, Feng XH. Smads: transcriptional activators of TGFbeta responses. Cell 1998;95:737-740.

6. Massague J, Wotton D. Transcriptional control by the TGF-beta/Smad signaling system. EMBO J 2000;19:1745-1754.

7. Han SU, Kim HT, Seong DH, et al. Loss of the Smad3 expression increases susceptibility to tumorigenicity in human gastric cancer. Oncogene 2004;23:1333-1341.

8. Kiyono K, Suzuki HI, Morishita Y, et al. c-Ski overexpression promotes tumor growth and angiogenesis through inhibition of transforming growth factor-beta signaling in diffuse-type gastric carcinoma. Cancer Sci 2009;100:1809-1816.

9. Park K, Kim SJ, Bang YJ, et al. Genetic changes in the transforming growth factor beta (TGF-beta) type II receptor gene in human gastric cancer cells: correlation with sensitivity to growth inhibition by TGFbeta. Proc Natl Acad Sci USA 1994;91:8772-8776.

10. Markowitz S, Wang J, Myeroff L, et al. Inactivation of the type II TGFbeta receptor in colon cancer cells with microsatellite instability. Science 1995;268:1336-1338.

11. Shitara $Y$, Yokozaki $H$, Yasui W, et al. No mutations of the Smad2 gene in human sporadic gastric carcinomas. Jpn J Clin Oncol 1999;29:3-7.

12. Xiangming $C$, Natsugoe $S$, Takao $S$, et al. Preserved Smad4 expression in the transforming growth factor beta signaling pathway is a favorable prognostic factor in patients with advanced gastric cancer. Clin Cancer Res 2001;7:277-282.

13. Kim JY, Park DY, Kim GH, et al. Smad4 expression in gastric adenoma and adenocarcinoma: frequent loss of expression in diffuse type of gastric adenocarcinoma. Histol Histopathol 2005;20:543-549.

14. Wang $\mathrm{LH}$, Kim $\mathrm{SH}$, Lee $\mathrm{JH}$, et al. Inactivation of SMAD4 tumor suppressor gene during gastric carcinoma progression. Clin Cancer Res 2007;13:102-110.

15. Xu X, Brodie SG, Yang $X$, et al. Haploid loss of the tumor suppressor Smad4/Dpc4 initiates gastric polyposis and cancer in mice. Oncogene 2000;19:1868-1874.

16. de Caestecker MP, Piek E, Roberts $A B$. Role of transforming growth factor-beta signaling in cancer. J Natl Cancer Inst 2000;92:1388-1402.

17. Sodir NM, Chen X, Park R, et al. Smad3 deficiency promotes tumorigenesis in the distal colon of ApcMin/+ mice. Cancer Res 2006; 66:8430-8438

18. Zhu Y, Richardson JA, Parada LF, et al. Smad3 mutant mice develop metastatic colorectal cancer. Cell 1998;94:703-714.

19. Datto MB, Frederick JP, Pan L, et al. Targeted disruption of Smad3 reveals an essential role in transforming growth factor beta-mediated signal transduction. Mol Cell Biol 1999;19:2495-2504.

20. Yang $X$, Letterio JJ, Lechleider RJ, et al. Targeted disruption of SMAD3 results in impaired mucosal immunity and diminished $T$ cell responsiveness to TGF-beta. EMBO J 1999;18:1280-1291.

21. Nozaki K, Ogawa M, Williams JA, et al. A molecular signature of gastric metaplasia arising in response to acute parietal cell loss. Gastroenterology 2008;134:511-522.

22. Chen HC, Chu RY, Hsu PN, et al. Loss of E-cadherin expression correlates with poor differentiation and invasion into adjacent organs in gastric adenocarcinomas. Cancer Lett 2003;201:97-106.

23. Almeida PR, Ferreira VA, Santos CC, et al. E-cadherin immunoexpression patterns in the characterisation of gastric carcinoma histotypes. J Clin Pathol 2010;63:635-639.

24. May $R$, Riehl TE, Hunt $C$, et al. Identification of a novel putative gastrointestinal stem cell and adenoma stem cell marker, doublecortin and CaM kinase-like-1, following radiation injury and in adenomatous polyposis coli/multiple intestinal neoplasia mice. Stem Cells 2008; 26:630-637. 
25. Gerbe F, Brulin B, Makrini L, et al. DCAMKL-1 expression identifies Tuft cells rather than stem cells in the adult mouse intestinal epithelium. Gastroenterology 2009;137:2179-2180.

26. Saqui-Salces M, Keeley TM, Grosse AS; et al. Gastric tuft cells express DCLK1 and are expanded in hyperplasia. Histochem Cell Bio 2011;136:191-204.

27. Sato A. Tuft cells. Anat Sci Int 2007;82:187-199.

28. Wong GT, Gannon KS, Margolskee RF. Transduction of bitter and sweet taste by gustducin. Nature 1996;381:796-800.

29. Hass N, Schwarzenbacher K, Breer H. A cluster of gustducin-expressing cells in the mouse stomach associated with two distinct populations of enteroendocrine cells. Histochem Cell Biol 2007;128:457-471.

30. Margolskee RF. Molecular mechanisms of bitter and sweet taste transduction. J Biol Chem 2002;277:1-4

31. Fox JG, Li X, Cahill RJ, et al. Hypertrophic gastropathy in Helicobacter felis-infected wild-type C57BL/6 mice and p53 hemizygous transgenic mice. Gastroenterology 1996;110:155-166.

32. Fox JG, Wang $T C$, Rogers $A B$, et al. Host and microbial constituents influence Helicobacter pylori-induced cancer in a murine model of hypergastrinemia. Gastroenterology 2003;124:1879-1890.

33. Nam KT, Oh SY, Ahn B, et al. Decreased Helicobacter pylori associated gastric carcinogenesis in mice lacking inducible nitric oxide synthase. Gut 2004;53:1250-1255.

34. Wang TC, Goldenring JR, Dangler C, et al. Mice lacking secretory phospholipase A2 show altered apoptosis and differentiation with Helicobacter felis infection. Gastroenterology 1998;114:675-689.

35. Nam KT, Varro A, Coffey RJ, et al. Potentiation of oxyntic atrophyinduced gastric metaplasia in amphiregulin-deficient mice. Gastroenterology 2007;132:1804-1819.

36. Nomura $\mathrm{S}$, Yamaguchi $\mathrm{H}$, Ogawa $\mathrm{M}$, et al. Alterations in gastric mucosal lineages induced by acute oxyntic atrophy in wild-type and gastrindeficient mice. Am J Physiol Gastrointest Liver Physiol 2005;288: G362-G375.

37. Yoshizawa N, Takenaka $\mathrm{Y}$, Yamaguchi $\mathrm{H}$, et al. Emergence of spasmolytic polypeptide-expressing metaplasia in Mongolian gerbils infected with Helicobacter pylori. Lab Invest 2007;87:1265-1276.

38. Judd LM, Alderman BM, Howlett M, et al. Gastric cancer development in mice lacking the SHP2 binding site on the IL-6 family co-receptor gp130. Gastroenterology 2004;126:196-207.

39. Kang W, Rathinavelu S, Samuelson LC, et al. Interferon gamma induction of gastric mucous neck cell hypertrophy. Lab Invest 2005 85:702-715.
40. Lefebvre O, Chenard MP, Masson R, et al. Gastric mucosa abnormalities and tumorigenesis in mice lacking the pS2 trefoil protein. Science 1996;274:259-262.

41. Eppert K, Scherer SW, Ozcelik $\mathrm{H}$, et al. MADR2 maps to $18 \mathrm{q} 21$ and encodes a TGFbeta-regulated MAD-related protein that is functionally mutated in colorectal carcinoma. Cell 1996;86:543-552.

42. Arai T, Akiyama $Y$, Okabe $S$, et al. Genomic structure of the human Smad3 gene and its infrequent alterations in colorectal cancers. Cancer Lett 1998;122:157-163.

43. Waldrip WR, Bikoff EK, Hoodless PA, et al. Smad2 signaling in extraembryonic tissues determines anterior-posterior polarity of the early mouse embryo. Cell 1998;92:797-808.

44. Hamamoto T, Beppu H, Okada H, et al. Compound disruption of smad2 accelerates malignant progression of intestinal tumors in apc knockout mice. Cancer Res 2002;62:5955-5961.

45. Maggio-Price $L$, Treuting $P$, Zeng $W$, et al. Helicobacter infection is required for inflammation and colon cancer in SMAD3-deficient mice. Cancer Res 2006;66:828-838.

46. Canfield V, West $A B$, Goldenring JR, et al. Genetic ablation of parietal cells in transgenic mice: a new model for analyzing cell lineage relationships in the gastric mucosa. Proc Natl Acad Sci USA 1996;93:2431-2435.

47. Barker N, Huch M, Kujala P, et al. Lgr5(+ve) stem cells drive self-renewal in the stomach and build long-lived gastric units in vitro. Cell Stem Cell 2010;6:25-36.

48. Wang $\mathrm{X}$, Ouyang $\mathrm{H}$, Yamamoto $\mathrm{Y}$, et al. Residual embryonic cells as precursors of a Barrett's-like metaplasia. Cell 2011;145:1023-1035.

49. Van Zanten SJ, Dixon MF, Lee A. The gastric transitional zones: neglected links between gastroduodenal pathology and helicobacter ecology. Gastroenterology 1999;116:1217-1229.

50. Karam SM, Leblond CP. Dynamics of epithelial cells in the corpus of the mouse stomach. I. Identification of proliferative cell types and pinpointing of the stem cell. Anat Rec 1993;236:259-279.

51. Giannakis M, Stappenbeck TS, Mills JC, et al. Molecular properties of adult mouse gastric and intestinal epithelial progenitors in their niches. J Biol Chem 2006;281:11292-11300.

52. Hofer D, Puschel B, Drenckhahn D. Taste receptor-like cells in the rat gut identified by expression of alpha-gustducin. Proc Natl Acad Sci USA 1996;93:6631-6634.

53. McLaughlin SK, McKinnon PJ, Margolskee RF. Gustducin is a taste-cellspecific $G$ protein closely related to the transducins. Nature 1992; 357:563-569. 